\title{
Synthesis of cis-hydrindan-2,4-diones bearing an all-carbon quaternary center by a Danheiser annulation
}

\author{
Gisela V. Saborit ${ }^{1}$, Carlos Cativiela ${ }^{2}$, Ana I. Jiménez ${ }^{2}$, Josep Bonjoch ${ }^{* 1}$ \\ and Ben Bradshaw*1
}

\section{Letter}

\section{Address:}

${ }^{1}$ Laboratori de Química Orgànica, Facultat de Farmàcia, IBUB, Universitat de Barcelona, Av. Joan XXIII s/n, 08028-Barcelona, Spain and ${ }^{2}$ Departamento de Química Orgánica Instituto de Síntesis Química y Catálisis Homogénea (ISQCH), CSIC-Universidad de Zaragoza, 50009 Zaragoza, Spain

Email:

Josep Bonjoch ${ }^{*}$ - josep.bonjoch@ub.edu; Ben Bradshaw* benbradshaw@ub.edu

* Corresponding author

Keywords:

alkaloid; Danheiser annulation; decahydroquinoline
Beilstein J. Org. Chem. 2018, 14, 2597-2601. doi:10.3762/bjoc. 14.237

Received: 24 July 2018

Accepted: 21 September 2018

Published: 09 October 2018

Associate Editor: A. Kirschning

(c) 2018 Saborit et al.; licensee Beilstein-Institut. License and terms: see end of document.

\begin{abstract}
A straightforward synthetic entry to functionalized hydrindane compounds based on a rapid assembly of the core nucleus by a Danheiser cycloaddition is reported. Valuable bicyclic building blocks containing the fused five and six-membered carbocyclic ring system can be achieved in only four steps from a simple acyclic $\beta$-keto ester.
\end{abstract}

\section{Introduction}

cis-Fused hydrindanes (bicyclo[4.3.0]nonanes) [1,2], scaffolds of numerous natural products, are amenable to application as advanced intermediates in the total synthesis of Lycopodium alkaloids [3-6], 3a-substituted 2,4-dicarbonyl compounds being particularly useful in this field. The synthetic approaches toward these versatile building blocks (i.e., compounds with the functionalization pattern A) are outlined in Figure 1, which for the sake of clarity omits the substituents not involved in the bond-forming step in the final ring closure. Almost all the strategies developed to date involve the formation of the $\mathrm{C} 3-\mathrm{C} 3 \mathrm{a}$ bond in the ring-closing step leading to the hydrindane nucleus. The carbocyclization takes place from polyfunctionalized cyclohexanones or related compounds through a Michael reaction [7], successive inter- and intramolecular radical processes [8], intramolecular carbene addition/cyclization [9,10], aldol cyclizations either under Lewis acid catalysis [11] or from diazoketones in the presence of bases (e.g., DBU) [12], Pd-catalyzed cycloalkenylation of a silyl enol ether [13], or basepromoted ynone carbocyclizations [14,15]. Another approach through an aldol cyclization, forming the $\mathrm{C} 1-\mathrm{C} 7$ a bond instead, has also been reported [16]. Different strategies were developed by Overman through ring-expanding cyclopentane 


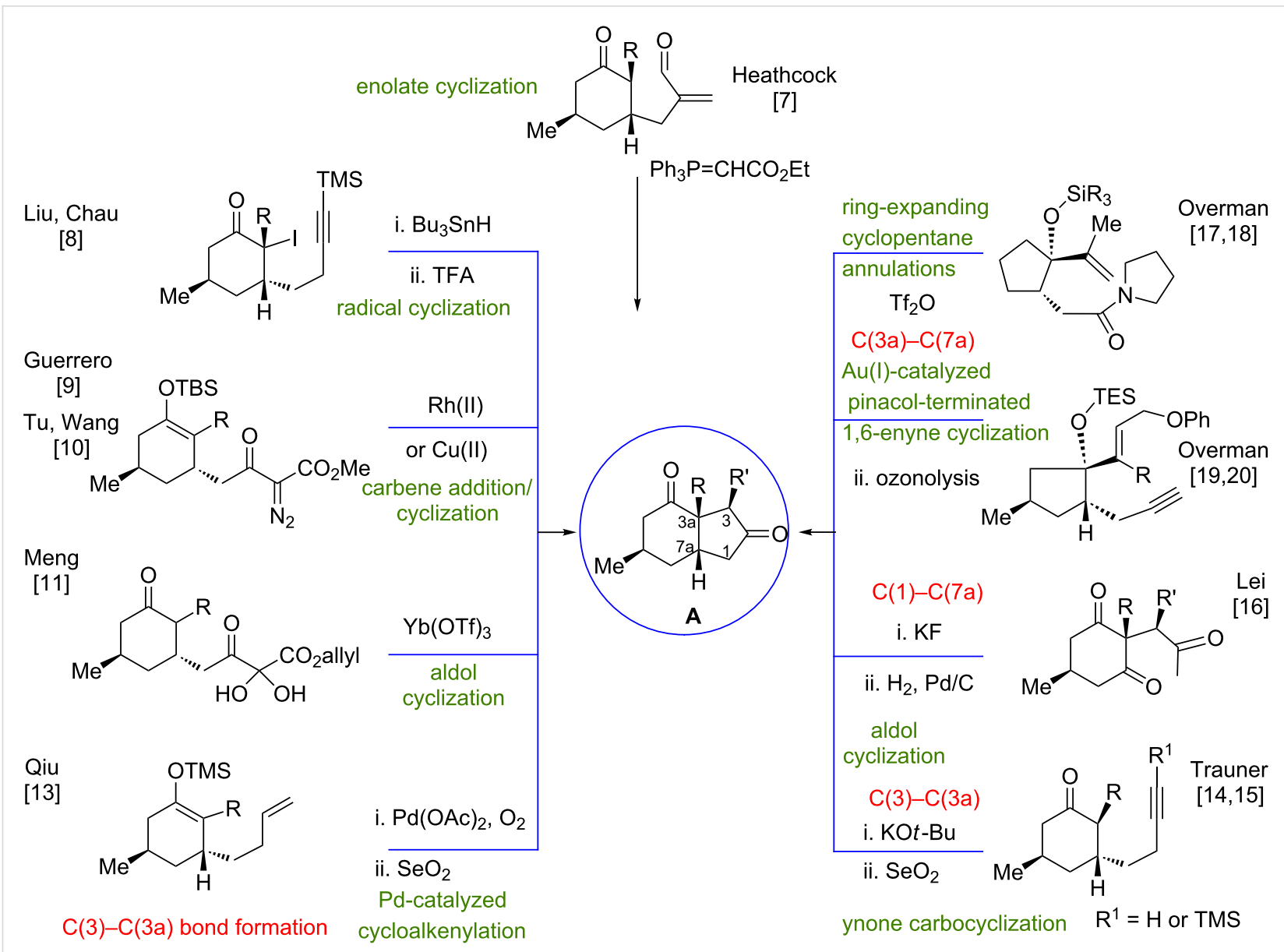

Figure 1: Previous synthetic approaches to 3a-substituted cis-hydrindan-2,4-diones.

annulations based on a Prins-pinacol rearrangement [17,18] and $\mathrm{Au}(\mathrm{I})$-catalyzed pinacol-terminated 1,6-enyne cyclizations $[19,20]$, the C3a-C7a bond formation occurring in the last step of both procedures. Finally, Snyder gained access to the type A hydrindane nucleus from an acyclic compound by a cascade radical process using $\mathrm{Mn}(\mathrm{OAc})_{3}$ [21], although a trans-fused ring system was formed. Also of note, is the approach of Mori [22] to a dihydroindenedione based on an initial cyclization of an allyl iodide in a 1,3-cyclohexanedione side chain via an allyl anion (generated by $\mathrm{Me}_{3} \mathrm{SiSnBu}_{3}$ and $\mathrm{CsF}$ ).
As a continuation of our work on the synthesis of Lycopodium alkaloids [23-26], we hypothesized that decahydroquinoline 1, a versatile building block for the synthesis of phlegmarine-type alkaloids, available in both enantiomeric forms, could also serve as an intermediate toward other Lycopodium alkaloids (e.g., fawcettimine). Thus, we surmised that building block 1 could be a new precursor of 3a-substituted hydrindan-2,4-diones (Scheme 1). This type of compounds, when adequately functionalized, has been used as advanced intermediates for the synthesis of the Lycopodium alkaloids carinatine A [11,14,15],

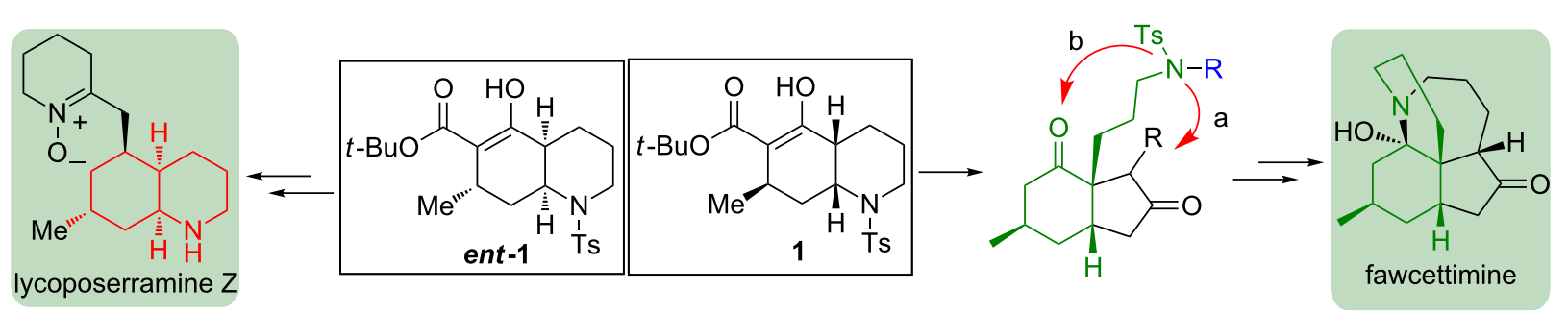

Scheme 1: Decahydroquinoline 1 as a versatile building block for Lycopodium alkaloid synthesis. 
8-deoxyserratinine [10], fawcettidine [10], fawcettimine [7,10], lycojaponicumin C [10], lycopladine A [11,13-15], lycoposerramine $\mathrm{R}[13,14]$, and sieboldine [19,20] (Figure 2).

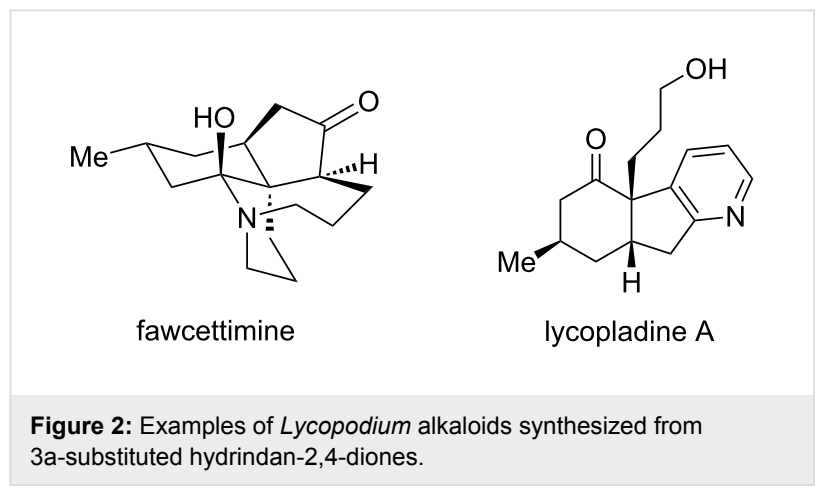

\section{Results and Discussion}

Despite the potential of [3+2] cycloaddition reactions [27] to achieve cis-hydrindan-2,4-diones, their application to rapidly assemble the five-membered ring of the targeted 6,5-bicylic system has not been reported until now. Two examples using cycloaddition processes in this field should be mentioned: Diels-Alder [28] and Pauson-Khand [29] reactions have been used to build the hydrindane bicyclic system, but incorporating a different functionalization pattern in the cyclic compounds.

Proposed here is a new methodological approach to functionalized 3a-substituted hydrindane synthesis based on a Danheiser annulation involving a $[3+2]$ cycloaddition reaction of a (trimethylsilyl)allene and a suitable cyclic $\alpha, \beta$-unsaturated ketone $[30,31]$. Despite the applicability of the reaction to construct five-membered rings, it has not been extensively examined [32] for the synthesis of complex natural products.
As depicted in Scheme 2, the hydrindane core ring would be assembled by the simultaneous formation of two $\mathrm{C}-\mathrm{C}$ bonds. This strategy is based on the disconnection across the $\mathrm{C} 1-\mathrm{C} 7 \mathrm{a}$ and $\mathrm{C} 3-\mathrm{C} 3 \mathrm{a}$ bonds, which according to the Danheiser annulation logic would reveal the cyclohexenone intermediate $\mathbf{I}$ and a silylallene such as II. The former, in turn, would disconnect back to $\beta$-keto ester 1 (Scheme 1), which we have employed in the synthesis of phlegmarine-type Lycopodium alkaloids [2326].<smiles>[R]CCC(=C=C)C(C)(C)C</smiles>

Danheiser [3 + 2] cycloaddition

Scheme 2: A de novo approach to 3a-substituted cis-hydrindan-2,4diones.

To prepare the starting material to evaluate the key Danheiser annulation reaction (Scheme 3), $\beta$-keto ester 2 was treated with crotonaldehyde and $\mathrm{LiOH}$ in $\mathrm{PrOH}$, following our previously developed procedure, to give decahydroquinoline 1 [23]. The removal of the tert-butyl ester group with TFA, followed by treatment with $\mathrm{LiOH}$ in refluxing THF promoted a retro-azaMichael reaction yielding the ring-opened product 3 [33]. The latter was trapped in situ with benzyl bromide to furnish cyclohexenone 4 in $86 \%$ overall yield over the two steps from 1 . Additionally, the overall transformation from the starting material 2 was also performed in a one-pot sequence involving six reac-<smiles>CC#CC[C@H]1C[C@H](C)CC(=O)[C@H]1CCCCN([As])Cc1ccccc1</smiles>

Scheme 3: Synthesis of enone 4 and the Danheiser annulation. The depicted compounds are all racemic. 
tions, namely, an intermolecular Michael reaction, aldol cyclization, intramolecular aza-Michael reaction, removal of a tertbutoxycarbonyl ester, base-promoted ring opening and tosylamide benzylation, without significant detrimental effect on the overall yield (see Supporting Information File 1).

With the key precursor 4 in hand, the stage was set to study the Danheiser annulation step. Gratifyingly, treatment of $\mathbf{4}$ with $\mathrm{TiCl}_{4}$ in the presence of commercially available 1-methyl-1-(trimethylsilyl)allene at $-78{ }^{\circ} \mathrm{C}$ for $1 \mathrm{~h}$ afforded the desired cis-6,5bicylic core 5 in $63 \%$ yield as a single diastereomer. The desilylated product 6 was also obtained as a mixture of diastereomers. The high stereoselectivity of the ring-formation step can be explained by the suprafacial addition of the allene to the double bond of the $\alpha, \beta$-unsaturated compound $\mathbf{4}$, the diastereoselectivity being sterically controlled by the methyl group on the $\beta$-face. The transformation of the vinylsilane moiety in $\mathbf{5}$ into the corresponding carbonyl group (Scheme 4) was carried out by a two-step procedure involving epoxidation of the vinylsilane 5 , followed by a rearrangement of the diastereomeric mixture of epoxides 7 induced by formic acid [34,35]. The resulting ketone 8 was obtained as a 3.5:1 mixture of epimers at C3.

The relative configuration of the major epimer of 8 (Figure 3) was established on the basis of a cross peak in the NOESY spectrum that correlated the methyl group at $\mathrm{C} 3$ with a methylene proton adjacent to the quaternary carbon of the side chain at $\mathrm{C} 3 \mathrm{a}$. The configuration at $\mathrm{C} 3$, adjacent to a carbonyl group, is not relevant for the potential application of this type of building block (i.e., 8) in fawcettimine and related alkaloid synthesis, since this stereogenic center is epimerizable, as shown by Heathcock [7].

\section{Conclusion}

In summary, we have successfully applied the Danheiser annulation reaction to rapidly assemble the 6,5-bicyclic nucleus of hydrindane compounds, expanding the usefulness of the versatile decahydroquinoline building block 1 . Although the com-

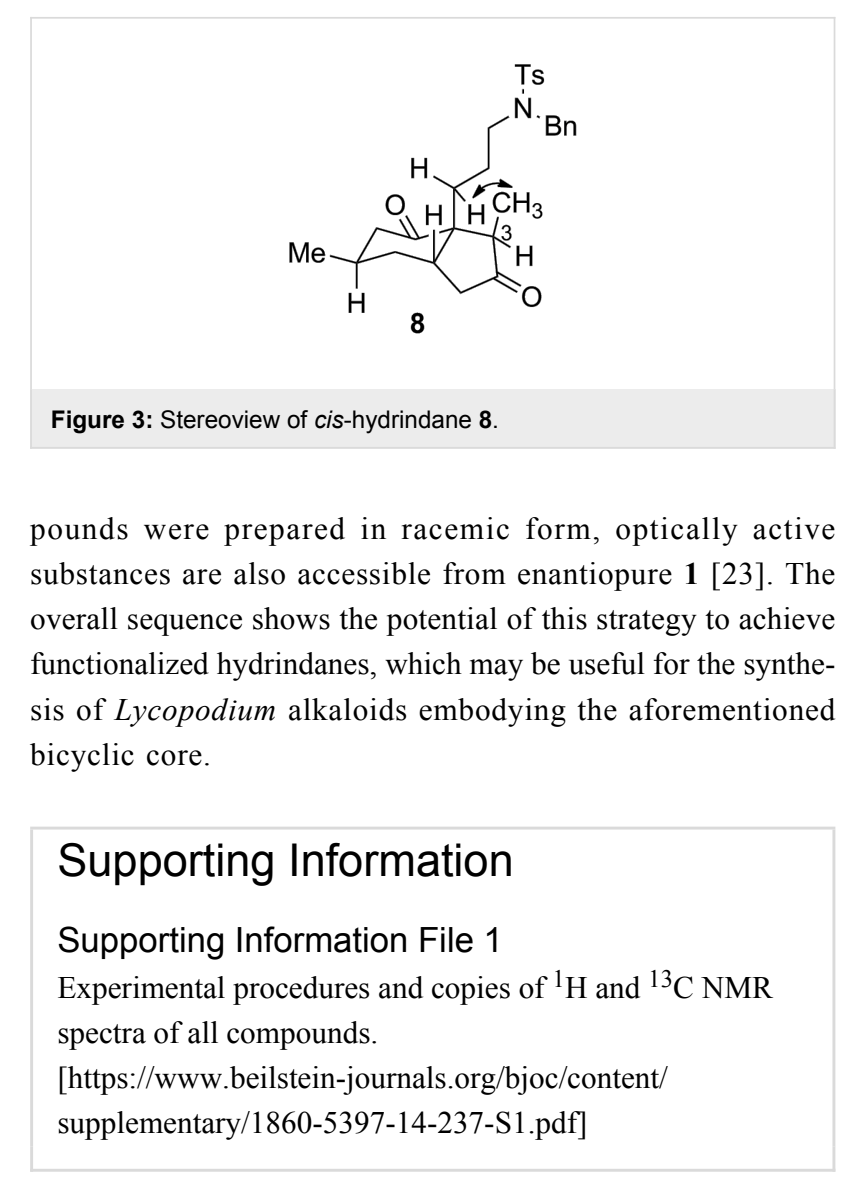

\section{Acknowledgements}

Financial support for this research was provided by Project CTQ2016-41338-P and CTQ2013-40855-R from the Ministry of Economy and Competitiveness of Spain (MINECO). Thanks are also due to Gobierno de Aragón-FEDER (research group E19_17R).

\section{ORCID ${ }^{\circledR}$ iDs}

Carlos Cativiela - https://orcid.org/0000-0003-3222-0828 Josep Bonjoch - https://orcid.org/0000-0002-5551-6720 Ben Bradshaw - https://orcid.org/0000-0001-9612-9199<smiles>CCCCC12C(=O)C[C@@H](C)C[C@H]1CC(C)=C2CCN([Te])Cc1ccccc1</smiles>

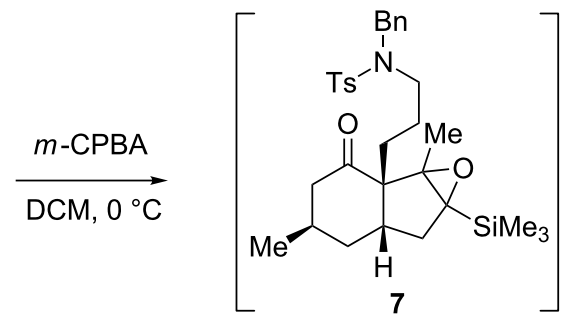

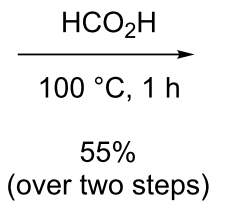




\section{References}

1. Findley, T. J. K.; Sucunza, D.; Miller, L. C.; Helm, M. D.; Helliwell, M.; Davies, D. T.; Procter, D. J. Org. Biomol. Chem. 2011, 9, 2433-2451. doi:10.1039/c0ob01086c

2. Liu, J.; Marsini, M. A.; Bedell, T. A.; Reider, P. J.; Sorensen, E. J. Tetrahedron 2016, 72, 3713-3717. doi:10.1016/j.tet.2016.03.039

3. Ma, X.; Gang, D. R. Nat. Prod. Rep. 2004, 21, 752-772. doi:10.1039/b409720n

4. Siengalewicz, P.; Mulzer, J.; Rinner, U. Lycopodium alkaloids: synthetic highlights and recent developments. The Alkaloids: Chemistry and Biology; Elsevier, 2013; Vol. 72, pp 1-151. doi:10.1016/B978-0-12-407774-4.00001-7

5. Murphy, R. A.; Sarpong, R. Chem. - Eur. J. 2014, 20, 42-56. doi:10.1002/chem.201303975

6. Zhang, J.; Wu, J.; Hong, B.; Ai, W.; Wang, X.; Li, H.; Lei, X. Nat. Commun. 2014, 5, No. 4614. doi:10.1038/ncomms5614

7. Heathcock, C. H.; Blumenkopf, T. A.; Smith, K. M. J. Org. Chem. 1989, 54, 1548-1562. doi:10.1021/jo00268a015

8. Liu, K.-M.; Chau, C.-M.; Sha, C.-K. Chem. Commun. 2008, 91-93. doi:10.1039/B714078A

9. Del Bel, M.; Rovira, A.; Guerrero, C. A. J. Am. Chem. Soc. 2013, 135, 12188-12191. doi:10.1021/ja4054866

10. Hou, S.-H.; Tu, Y.-Q.; Liu, L.; Zhang, F.-M.; Wang, S.-H.; Zhang, X.-M. Angew. Chem., Int. Ed. 2013, 52, 11373-11376. doi:10.1002/anie.201306369

11. Meng, L. J. Org. Chem. 2016, 81, 7784-7789. doi:10.1021/acs.joc.6b01435

12. Li, Z.; Lam, S. M.; Ip, I.; Wong, W.-t.; Chiu, P. Org. Lett. 2017, 19, 4464-4467. doi:10.1021/acs.orglett.7b01963

13. Chen, S.; Wang, J.; Qiu, F. G. Chem. Commun. 2018, 54, 3598-3600. doi:10.1039/C8CC01626G

14. Hartrampf, F. W. W.; Furukawa, T.; Trauner, D. Angew. Chem., Int. Ed. 2017, 56, 893-896. doi:10.1002/anie.201610021

15. Hartrampf, F. W. W.; Trauner, D. J. Org. Chem. 2017, 82, 8206-8212. doi:10.1021/acs.joc.7b00908

16. Lei, S. RSC Adv. 2013, 3, 11014-11020. doi:10.1039/c3ra41467a

17. Hirst, G. C.; Howard, P. N.; Overman, L. E. J. Am. Chem. Soc. 1989, 111, 1514-1515. doi:10.1021/ja00186a065

18. Overman, L. E.; Wolfe, J. P. J. Org. Chem. 2002, 67, 6421-6429. doi:10.1021/jo025927r

19. Canham, S. M.; France, D. J.; Overman, L. E. J. Org. Chem. 2013, 78, 9-34. doi:10.1021/jo300872y

20. Canham, S. M.; France, D. J.; Overman, J. E. J. Am. Chem. Soc. 2010, 132, 7876-7877. doi:10.1021/ja103666n

21. Snider, B. B.; Buckman, B. O. J. Org. Chem. 1992, 57, 322-326. doi:10.1021/jo00027a056

22. Kinoshita, A.; Mori, M. Chem. Lett. 1994, 1475-1478. doi:10.1246/cl.1994.1475

23. Bradshaw, B.; Luque-Corredera, C.; Bonjoch, J. Org. Lett. 2013, 15, 326-329. doi:10.1021/ol303257y

24. Bradshaw, B.; Luque-Corredera, C.; Bonjoch, J. Chem. Commun. 2014, 50, 7099-7102. doi:10.1039/C4CC01708K

25. Bosch, C.; Fiser, B.; Gómez-Bengoa, E.; Bradshaw, B.; Bonjoch, J. Org. Lett. 2015, 17, 5084-5087. doi:10.1021/acs.orglett.5b02581

26. Saborit, G. V.; Bosch, C.; Parella, T.; Bradshaw, B.; Bonjoch, J. J. Org. Chem. 2016, 81, 2629-2634. doi:10.1021/acs.joc.6b00025

27. López, F.; Mascareñas, J. L. Chem. - Eur. J. 2011, 17, 418-428. doi:10.1002/chem.201002366

28. Zaimoku, H.; Taniguchi, T. Chem. - Eur. J. 2014, 20, 9613-9619. doi:10.1002/chem.201403163
29. Otsuka, Y.; Inagaki, F.; Mukai, C. J. Org. Chem. 2010, 75, 3420-3426. doi:10.1021/jo100499h

30. Danheiser, R. L.; Carini, D. J.; Basak, A. J. Am. Chem. Soc. 1981, 103, 1604-1606. doi:10.1021/ja00396a071

31. Danheiser, R. L.; Carini, D. J.; Fink, D. M.; Basak, A. Tetrahedron 1983, 39, 935-947. doi:10.1016/S0040-4020(01)88592-6

32. Friese, J. C.; Krause, S.; Schäfer, H. J. Tetrahedron Lett. 2002, 43, 2683-2685. doi:10.1016/S0040-4039(02)00402-1

33. Bradshaw, B.; Luque-Corredera, C.; Saborit, G.; Cativiela, C.; Dorel, R.; Bo, C.; Bonjoch, J. Chem. - Eur. J. 2013, 19, 13881-13892. doi:10.1002/chem.201301715

34. Choi, J.-K.; Hart, D. J. Tetrahedron 1985, 41, 3959-3971. doi:10.1016/S0040-4020(01)97176-5

35. May, T. L.; Dabrowski, J. A.; Hoveyda, A. H. J. Am. Chem. Soc. 2011, 133, 736-739. doi:10.1021/ja110054q

\section{License and Terms}

This is an Open Access article under the terms of the Creative Commons Attribution License (http://creativecommons.org/licenses/by/4.0). Please note that the reuse, redistribution and reproduction in particular requires that the authors and source are credited.

The license is subject to the Beilstein Journal of Organic Chemistry terms and conditions: (https://www.beilstein-journals.org/bjoc)

The definitive version of this article is the electronic one which can be found at: doi: $10.3762 /$ bjoc. 14.237 